\title{
ESPACIAMIENTO INTERCULTURAL: LA CONSTRUCCIÓN DEL TERRITORIO SIMBÓLICO Y SUS CARTOGRAFÍAS ÉTICO-ESTÉTICAS COMO MEMORIA VISUAL DE LOS PROCESOS DE PERTENENCIA EN LIMA METROPOLITANA
}

\author{
Karla Villavicencio Monti \\ Pontificia Universidad Católica del Perú
}

Resumen: En el presente artículo se intenta exponer las posibilidades de representación simbólica del territorio desde un enfoque interdisciplinario del arte y la arquitectura. De esta manera, se desarrolla una metodología que, aplicada a las problemáticas periféricas del territorio y a su reconstrucción, posibilite la visualización de un patrimonio cultural inmaterial, el cual será expresado en la producción de cartografías imaginarias. Estas cartografías simbolizan valores éticoestéticos mediante la representación de la memoria visual contenida en los procesos de pertenencia dados en la ciudad de Lima Metropolitana. ¿Cómo podríamos visibilizar los procesos de reconstrucción que realiza nuestra memoria en torno a los espacios donde vivimos y participamos? Nuestra propuesta es una metodología con base en tres fases del reconocimiento simbólico: la primera se inicia con una ruta personal de reordenamiento y reconstrucción de la propia identidad, a través del conocimiento topográfico del territorio; la segunda, con el desarrollo de bosquejos cartográficos que promuevan la visualización de la intersubjetividad contenida en los procesos de las problemáticas colectivas de la ciudad; y la tercera, con la identificación y visibilización del valor patrimonial contenido en los componentes ético-estéticos de la convivencia social. Esta metodología será explicada mediante el desarrollo de tres proyectos, dos de ellos son obras plásticas e instalativas individuales, «De Reducto 2 a la Portada de Maravillas. Hacia el descanso» $y$ «Nuestra ruta de 50 años», mientras que el tercero es grupal: «CO[HABITAR]». Podemos reconocer que la visualización mediante la expresión cartográfica de las problemáticas colectivas de la ciudad, desde sus aspectos simbólicos, representa diversas posibilidades de reconocimiento de los acontecimientos vivenciados en el territorio. Esta visualización presenta diversas capas de comprensión, 
subjetiva e intersubjetiva, que se relacionan estrechamente con las experiencias culturales y sociopolíticas de sus participantes.

Palabras clave: arquitectura, arte, urbanismo, territorio simbólico, Lima Metropolitana.

\title{
Intercultural Spacing: The Construction of Symbolic Territory and Its Ethical-Aesthetic Cartographies as Visual Memory of Belonging Processes in Lima Metropolitana
}

\begin{abstract}
It is attempted to show the possibilities of symbolic representation under an interdisciplinary approach, from Art and Architecture applied to the peripheral problems of the environment and to their reconstruction from the territory, evidencing a symbolic heritage based on the production of cartographies that show ethicalaesthetic values as a possibility of representation of the visual memory contained in the belonging processes occurring in the city of Metropolitan Lima.

How could we view these reconstruction processes made by our memory around the spaces where we live and participate or how could migration paths be evidenced from that perspective?

A methodology is proposed based on three phases of recognition of a personal route of rearrangement of individual history which starts from topographic knowledge of the territory in the reconstruction of personal experiences, to develop then cartographic sketches for the viewing of their implication in the reading of migration processes, as well as collective problems.

This methodology will be explained through the development of three specific projects. Individual visual and installation artworks «De Reducto n. 2 a la Portada de Maravillas: Hacia el Descanso», «La Ruta de 50 Años» and Group Project «CO(HABITAR)».

It can be recognized that the viewing of migration processes, from their symbolic aspects, represent diverse variants of recognition of the events experienced in the territory implying various layers of a reading that before being illustrative could be viewed through the processes of artistic expression, depending on the different origins of their participants and their experiences in the city. Those processes reconstruct the time lived as a cartographic set that can be viewed.
\end{abstract}

Keywords: Architecture, Art, Urbanism, Symbolic Territory, Metropolitan Lima 
LA CONSTRUCCIÓN DEL TERRITORIO SIMBÓLICO Y SUS CARTOGRAFÍAS ÉTICO-ESTÉTICAS COMO MEMORIA VISUAL DE LOS PROCESOS DE PERTENENCIA... / KARLA VillaVicEnCIO MonTi

\section{Karla Villavicencio Monti}

Doctora en Arquitectura por la Universidad Europea de Madrid y Licenciada en Arte por la PUCP. Es profesora auxiliar de la Facultad de Arte y Diseño de la Pontificia Universidad Católica del Perú desde 2017. En 2007-2008 fue asistente de investigación para el curso «Elementos del Proyecto Arquitectónico» en la Facultad de Arte y Arquitectura de la Universidad Europea de Madrid. En 2014 dirigió su documental ImaRginäre Städte / Ciudades imaRginales, que recibió el Premio StartStipendium financiado por el Ministerio de Arte, Cultura y Educación de Austria. En 2019 tuvo una estancia de investigación postdoctoral DARI-KAAD en la Universidad de Arte de Berlín y en 2020 dictó cátedra como profesora visitante en la Carrera de Arquitectura de la Universidad de Arte de Berlín. Al desarrollar sus proyectos interdisciplinarios, enfatiza los valores ético-estéticos y urbanos de los asentamientos en las periferias de la ciudad de Lima, promoviendo la visualización del patrimonio cultural inmaterial, que se inserta en la memoria visual y simbólica de estos procesos.

La autora agradece a la Dra. Susanne Hauser y al Akademischer AusländerDienst (KAAD) y a la Dirección Académica de Relaciones Institucionales (DARI) de la PUCP, por la estancia postdoctoral de investigación en la UDK Universität der Künste Berlín durante el año 2019.

Correo electronico: karla.villavicencio@pucp.pe 


\section{Introducción}

Investigando los fenómenos de los asentamientos humanos construidos sin legitimación del Estado en Lima Metropolitana por migrantes que se movilizaron a partir de los años cincuenta por una necesidad de subsistencia, se pudo observar que la autoconstrucción y el desarrollo urbano, junto a los factores sociales y culturales de la población más vulnerable de nuestro país, si bien conformaron un proceso caótico no previsto, manifestaron el desarrollo de principios urbano-contemporáneos articulados a los de las culturas prehispánicas. Es decir, se pudo constatar que sus participantes posicionaron su nuevo estadio a conquistar en Lima, creando nuevas perspectivas que a partir de allí se tomaron en cuenta para las investigaciones posteriores realizadas a través de aplicaciones metodológicas.

Desde esa valoración, trabajamos en la identificación de las problemáticas del territorio desde la visualización de los procesos personales como recorridos identificatorios de las diversidades culturales. A partir de una «singularidad habitada», nos propusimos imaginar, desde la comprensión de lo que nos es aparentemente ajeno o distinto, una colectividad «habitada» $\mathrm{y}$ «capaz de habitarse».

¿Cómo visualizar las cartografías simbólicas de «lo diverso» para que puedan ser expresadas e imaginadas? Consideraríamos diseñar un bosquejo a modo de espirales que, aunque separadas y desarticuladas, sean más flexibles, con posibilidades distintas de «pensarse» topográficamente. Pensemos que una espiral es una línea que se curva generando un círculo que no se cierra, y que transita de afuera hacia dentro o en un orden inverso; pero además consideremos imaginar la sumatoria de varias de ellas, en cuyas intersecciones se encuentre el potencial del diseño de una ciudad posible para quienes deban volver a transitar el regreso a su punto de partida.

El objetivo de este artículo es demostrar que, a través de la memoria, el habitante construye una cartografía simbólica donde unifica sus recorridos de tránsito y migración con procesos analíticovisuales de reconstrucción. Esta valoración simbólica debe ser atendida y defendida, ya que desde ella se forjan aspiraciones que muchas veces son invisibilizadas, pero que constituyen nuestro patrimonio inmaterial más preciado: el que expresa la memoria contenida en la experiencia ético-estética de la realidad que nos circunda. 
LA CONSTRUCCIÓN DEL TERRITORIO SIMBÓLICO Y SUS CARTOGRAFÍAS ÉTICO-ESTÉTICAS COMO MEMORIA VISUAL DE LOS PROCESOS DE PERTENENCIA... / KARLA VILLAVICENCIO MONTI

\section{Contenido}

Mediante investigaciones anteriores y la aplicación metodológica en los procesos de las mismas, se ha establecido la posibilidad de abordar el diseño de cartografías según el desarrollo de componentes simbólicos, mediante ejercicios secuenciados que hacen posible su visualización en diferentes etapas de la vida. Esta afirmación será comprendida mediante la explicación de documentos gráficos elaborados por los participantes de los seminarios y cursos a los que se hará referencia, en donde la base de la producción visual era la elaboración de dichas cartografías. La documentación visual que presentamos nos permitirá apreciar la visualización de dichas estructuras, realizadas desde el análisis del contexto territorial, político y social de las zonas estudiadas. A su vez, podremos apreciar los componentes éticoestéticos de las intervenciones en los espacios geográficos estudiados, a través del análisis de los métodos procesuales artísticos.

Para situarnos en el contexto de los casos expuestos, es importante contextualizar la historia a partir de los años cincuenta en Lima Metropolitana. A partir de entonces los migrantes posicionaron su nuevo estadio de conquista en Lima Metropolitana, accionar heredado desde la cultura andina, como lo reitera bien Ansión:

En un país como el Perú, las migraciones de ese tipo recuerdan una realidad conocida. Las sociedades andinas, en efecto, se han movido desde siempre de manera muy dinámica para aprovechar el potencial de los diversos nichos ecológicos dentro de estrategias familiares que suponen el desplazamiento de miembros del antiguo ayllu. Actualmente, las familias, desde sus diversos lugares de ocupación, apuntan a lograr como conjunto el aprovechamiento óptimo de los recursos de cada nicho (véase Murra 1975). Los grandes procesos migratorios internos hacia la ciudad (especialmente hacia Lima) en la segunda mitad del siglo xx obedecieron, al menos en sus inicios, a una lógica similar en la que Lima representaba el nuevo piso ecológico que debía ser conquistado. Estos procesos migratorios internos fueron facilitados, sin duda, por la experiencia histórica y cultural de los desplazamientos dentro de la lógica señalada ${ }^{1}$. (Ansión, Mujica \& Villacorta 2008: 39)

La experimentación del espacio territorial, por tanto, fue la de un contenedor de procesos de afincamiento que no necesariamente son dados exclusivamente en el territorio topográfico, sino ante todo en la construcción del espacio como un lugar de «tránsito» y de "pertenencia» sujeto a la

\footnotetext{
1 En referencia al texto (Ansión et al. 2008), los autores han estudiado diversas modalidades de las estrategias de incorporación de los migrantes en Lima.
} 
posibilidad de mutar y de transformarse. En la forma en la que habita el que migra, se establece una relación intrínseca entre aquello que le pertenece y lo que puede pertenecerle. Existe una estructura psíquico-simbólica en el afincamiento a un nuevo territorio.

La historia de quienes migraron del interior de país hacia Lima Metropolitana asentándose en las periferias, generalmente empezó en la zona de la que partieron. La familia depositó en los que se fueron las expectativas de nuevas posibilidades de desarrollo, para así poder tener acceso a los recursos que en un gobierno centralizado no les fueron dados. Estos pobladores, al construir los primeros límites de su vivienda, incursionaban en el nuevo territorio intentando una unificación socioeconómica: la del desplazado. En dicho territorio, el hábitat adquiere forma simbólica y constituye una envoltura protectora, en cuyo interior se encuentra un espacio de contención donde imaginación y memoria se entrelazan.

De esta manera, la voluntad comunitaria y sus acciones de afincamiento gestaron valores donde los hechos cronológicos, las expectativas y el devenir iban de la mano. Esta intimidad generada desde lo común fue en muchos casos el motor generador de estas viviendas contemporáneas en las periferias de Lima. La solidaridad fue el pilar que garantizó el desarrollo de muchos de estos espacios efímeros en nuevos distritos.

A lo largo de nuestra investigación comprobamos que las comunidades que llegaron a desarrollarse como ciudades, comprendiendo nuevos distritos, fueron aquellas donde el trabajo en equipo, la organización, la planificación política y la de su construcción estaban por encima de las necesidades individuales. Sin lugar a duda, esta capacidad de proyección común deriva del pasado: la sociedad incaica, por ejemplo, se caracterizó por el trabajo comunitario y una proyección urbanística estudiada previamente a la puesta en marcha de la constitución arquitectónica y urbana de la ciudad.

Existe una profunda complicidad en estos hechos comunitarios, podríamos hablar de una «intimidad del pueblo» que se contrapone muchas veces a la intimidad entendida como individualidad, promovida por las sociedades occidentales:

Si hoy se preguntase a cualquier habitante de las sociedades occidentales urbanizadas y pos-avanzadas por el significado del término «intimidad», es más que probable que las representaciones que con mayor rapidez acudieran a su mente fueran la «soledad» y la «autenticidad». Está muy extendida la creencia de que únicamente a solas podemos ser lo que genuinamente somos, y de que en ello radica la intimidad (falacia del solipsismo). (Pardo 1996: 140) 
LA CONSTRUCCIÓN DEL TERRITORIO SIMBÓLICO Y SUS CARTOGRAFÍAS ÉTICO-ESTÉTICAS COMO MEMORIA VISUAL DE LOS PROCESOS DE PERTENENCIA... / KARLA VilLAVICENCIO MONTI

Un ejemplo de esto fue demostrado en el documental ImaRginäre Städte (Ciudades imaRginales) (Villavicencio \& Luque 2014), que, a modo de registro de la memoria visual contenida en los procesos sociales y creativos en el territorio de la metrópolis contemporánea, establece un recorrido en paralelo entre la toma de «territorio ilegal» en dos ciudades muy distintas. Se enuncia «ilegal» con el objetivo de aclarar que hablamos de historias de territorios que no tuvieron reconocimiento ni ayuda del Estado para que puedan legalmente pertenecer a él y hacer viable la atención a las exigencias de sus habitantes, lo cual les imposibilitó insertarse a la ciudad reconocida por el Estado.

El documental trata la evolución de la ciudad y sus procesos urbanosociales en sociedades multiculturales. Se filmó en Lima y en Viena con la colaboración de otros cineastas que hicieron posible agrupar un archivo visual de la evolución de las historias narradas. En la historia de Villa El Salvador (Lima) se observa el nacimiento de este distrito en 1971, tras las exigencias de sus pobladores, con un auspicio gubernamental de la reubicación de los primeros invasores en un árido y alejado arenal al suroeste de Lima. El clima político de ese momento era el de una dictadura militar, iniciada en 1968 con Velasco, para la cual Villa El Salvador constituyó un desafío. Es en ese contexto que se crea la Comunidad Autogestionaria de Villa El Salvador (Cuaves).

La característica más importante de esta experiencia fue la capacidad organizativa de sus pobladores. Miguel Romero Sotelo fue el autor del diseño urbano y respondió a las demandas de un diseño que, por un lado, promoviera la organización y la participación de los pobladores que habían desarrollado un sistema de autogobierno y autogestión importante, y que, por otro, priorizara las redes sociales que le daban sentido a la convivencia de todos sus pobladores. Villa El Salvador fue el asentamiento humano más conocido del Perú, ganador de muchos premios nacionales y extranjeros por su esfuerzo colectivo, capacidad y creatividad popular, y por su organización fundada sobre bases democráticas. Un asentamiento que intentó conjugar las necesidades de construcción, producción y vivienda mediante su proyecto de autogobierno comunal.

Kahatt lo enuncia bien en su siguiente precisión:

Uno de los retosimportantes para estos «barrios» instalados en pendientes es vincular la movilidad con la vivienda y el espacio público. Para ello, resulta clave el entendimiento de la geografía y el manejo topográfico del lugar. El reconocimiento ofrece al paisajismo lo necesario para crear una nueva realidad. En muchos de los casos se asume - equivocadamenteque las viviendas construidas en pendientes «imposibles de habitar» (a $45^{\circ}$ o más) están ahí para quedarse para siempre. Sin embargo, esto 
no necesariamente tiene que ser así. Para poder proyectar un ambiente seguro, adecuado, hay que ser conscientes de que «así como llegaron» (por circunstancias desfavorables), pueden trasladarse a otros lugares en mejores condiciones o reubicarse en estos mismos lugares, pero en mejores escenarios, habitando una infraestructura colectiva, dotada de servicios y equipamiento público. (2016: 71)

Por otro lado, se muestra la historia de los Wagenplätze (Viena), donde grupos de casas-móviles ocupan territorio vienés de «forma ilegal», como una crítica al capitalismo desde un posicionamiento anarquista.

El punto de encuentro al que se llegó en ambas historias es a un significado del territorio donde la arquitectura no es inmóvil y perenne, sino que representa estructuras de contención de un proceso de afincamiento, donde la solidaridad y la autoorganización son cruciales para el desarrollo del grupo de habitantes, desafiando las reglas, los límites y la marginalización de la política de Estado y de la propia sociedad.

Dentro de la línea de investigación iniciada con el documental anteriormente mencionado, continuamos con la publicación del proyecto Metrópolis Imaginal: la guía de viajes simbólicos en Lima (Villavicencio et al. 2017), iniciado en 2016 y publicado en 2017, donde se estableció la formulación metodológica referida en la introducción. Metrópolis Imaginal consistió en un taller-seminario donde se trabajó con profesores de Arte de la Facultad de Arte y Diseño de la Pontificia Universidad Católica del Perú. Se definieron tres fases de producción de cartografías, cuyos procesos se enunciaron como los de mapificación, donde los participantes desarrollaron sus propias cartografías bajo las premisas del mapa personal, mapa histórico y mapa imaginal, valiéndose de cartografías del lugar elegido, así como de imágenes de archivo o producidas por ellos mismos, de las cuales surgiría una lectura simbólica del territorio.

En el desarrollo del mapa personal, los participantes exploraron la ubicación de cada integrante en la cartografía de su propia historia, considerando como elementos importantes los recuerdos estructurales que sostienen la lectura de su propio movimiento simbólico en el tiempo cronológico. En el desarrollo del mapa histórico, exploraron y analizaron, mediante excursiones en la ciudad y el redescubrimiento de sus lugares y recorridos, los componentes ético-estéticos, políticos y culturales de la ciudad actual. La última etapa correspondió al mapa imaginal, en la cual elaboraron cartografías con el objetivo de visibilizar las problemáticas y las preocupaciones en torno a la ciudad que surgían tras las dos experiencias anteriores, lo cual permitió el desarrollo de esquemas posibles de intervenciones simbólicas desde sus propios imaginarios. Esta metodología hizo factible imaginar el espacio como una construcción simbólica colectiva. 
LA CONSTRUCCIÓN DEL TERRITORIO SIMBÓLICO Y SUS CARTOGRAFÍAS ÉTICO-ESTÉTICAS COMO MEMORIA VISUAL DE LOS PROCESOS DE PERTENENCIA... / KARLA VILLAVICENCIO MONTI

En línea con estas tres fases del seminario Metrópolis Imaginal, explicaremos a continuación el desarrollo de los proyectos de dos de sus participantes. En primer término, el mapa imaginal de Cecilia Chávez, «Ruta de Reducto 2 a la Portada de Maravillas. Hacia el descanso»y, luego, el mapa imaginal de Ignacio Macha, «Nuestra ruta de 50 años».

\section{«Ruta de Reducto 2 a la Portada de Maravillas. Hacia el descanso»}

La artista Cecilia Chávez ${ }^{2}$, autora del proyecto, propone la elaboración de una ruta simbólica mediante el uso de mapas sobre la base de referencias históricas y personales (recuerdos de la infancia), para guiar a los soldados caídos en la batalla de Miraflores (1881, durante la guerra del Pacífico) hacia un lugar de descanso. Estos mapas están hechos en acrílico transparente sobreponiéndose la visualización de unos con respecto a los otros.

El interés por los fenecidos en esta batalla surge de un recuerdo infantil de la autora debido a que la vivienda donde creció quedaba cerca del parque Reducto n. ${ }^{\circ}$ 2. Ella aprovecha la ubicación de su vivienda y las historias que se contaban sobre el parque. Una de estas historias cuenta que los muertos en esta batalla estaban enterrados y que, al morir violentamente, nunca fueron conscientes de su muerte y no tienen reposo. En ese sentido, los mapas propuestos (véase las figuras) servirían de guía a los soldados caídos para que pudieran trasladarse a un lugar de descanso.

Los mapas que se explican a continuación y que pueden observarse en las siguientes páginas pertenecen a la producción de la artista. El primer mapa (Figura 3) aparece en transparencia como inicio de la ruta del recorrido anteriormente mencionado. En el siguiente mapa (Figura 4) aparecen los emplazamientos de las tropas peruanas y chilenas. El tercer y cuarto mapa (Figuras 5 y 6) son del tren Chorrillos-Lima, que es la ruta que deben seguir los difuntos; luego la ruta se dirige a la estación de tren dentro de la muralla de la Lima Antigua y desde ahí sigue por las calles hasta la Portada de Maravillas, derribada en 1868, cuyos rezagos todavía existen, y la cual los conduciría al descanso en el cementerio Presbítero Maestro (Chávez 2017).

\footnotetext{
2 Cecilia Chávez, docente de la Facultad de Arte y Diseño de la Pontificia Universidad Católica del Perú, autora del proyecto «De Reducto 2 a la Portada de Maravillas. Hacia el descanso», desarrollado en el proyecto «Metrópolis imaginal: la guía de los viajes simbólicos en Lima» en 2017, a cargo de la doctora Karla Villavicencio Monti, en el marco de la Cátedra Felipe Mac Gregor de Profesores Invitados 2016 PUCP.
} 


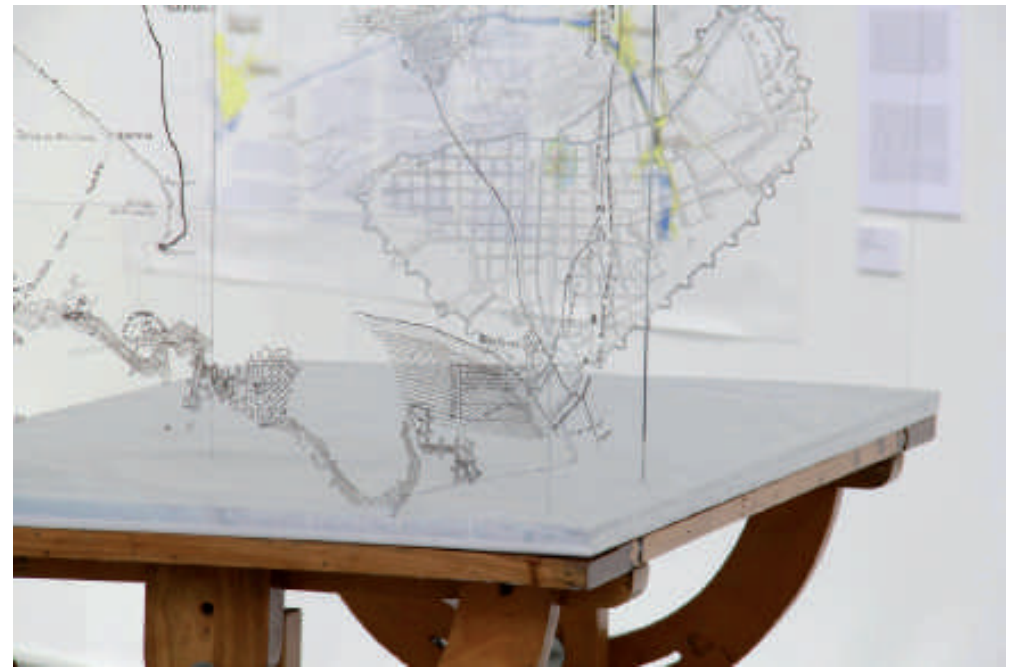

Figura 1. «De Reducto 2 a la Portada de Maravillas. Hacia el descanso». Plancha de acrílico, impresión sobre papel de plano, papel ingeniero, mesa de dibujo y banco de madera. Medidas variables (detalle). Fuente y elaboración: Chávez 2017: 20.

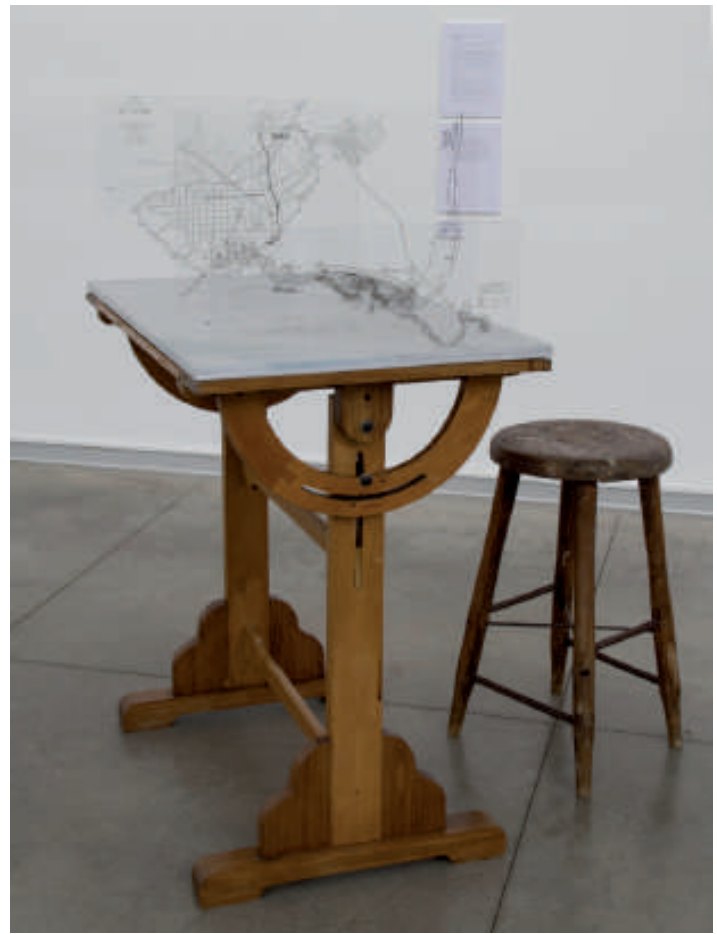

Figura 2. «De Reducto 2 a la Portada de Maravillas. Hacia el descanso». Plancha de acrílico, impresión sobre papel de plano, papel ingeniero, mesa de dibujo y banco de madera. Medidas variables. Fuente y elaboración: Chávez 2017: 20. 
LA CONSTRUCCIÓN DEL TERRITORIO SIMBÓLICO Y SUS CARTOGRAFÍAS ÉTICO-ESTÉTICAS COMO MEMORIA VISUAL DE LOS PROCESOS DE PERTENENCIA... / KARLA VILLAVICENCIO MONTI

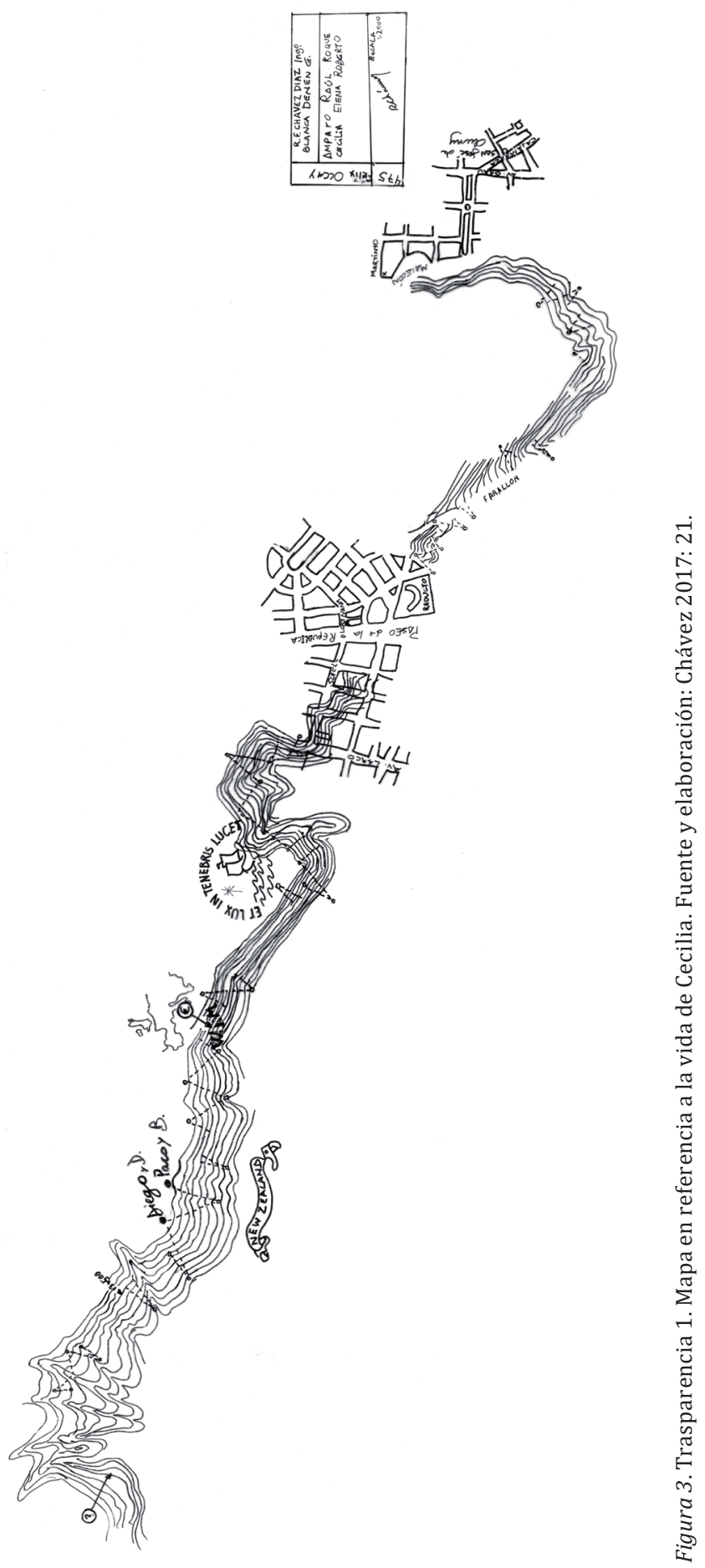




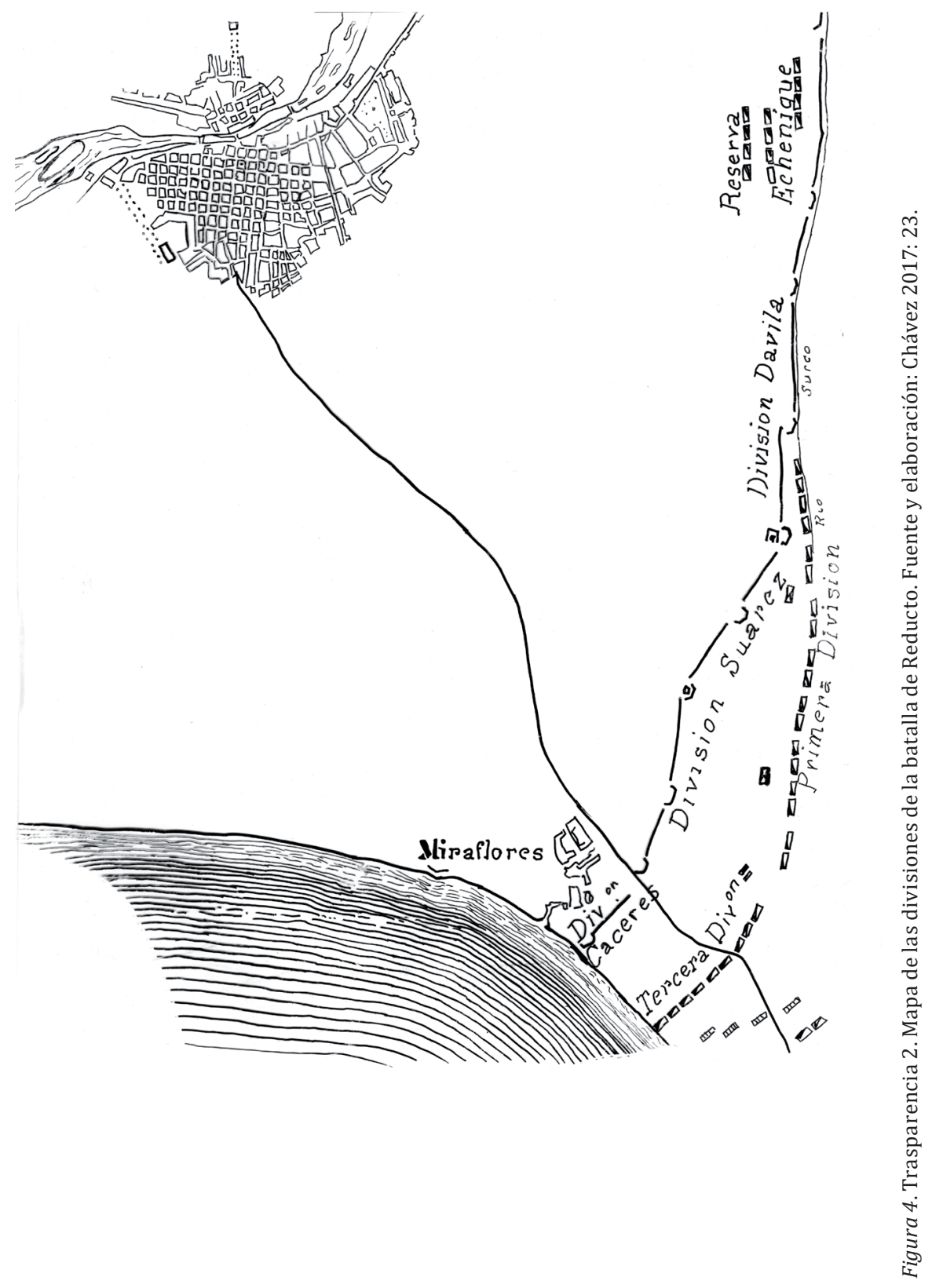


LA CONSTRUCCIÓN DEL TERRITORIO SIMBÓLICO Y SUS CARTOGRAFÍAS ÉTICO-ESTÉTICAS COMO MEMORIA VISUAL DE LOS PROCESOS DE PERTENENCIA... / KARLA VilLAVICENCIO MONTI

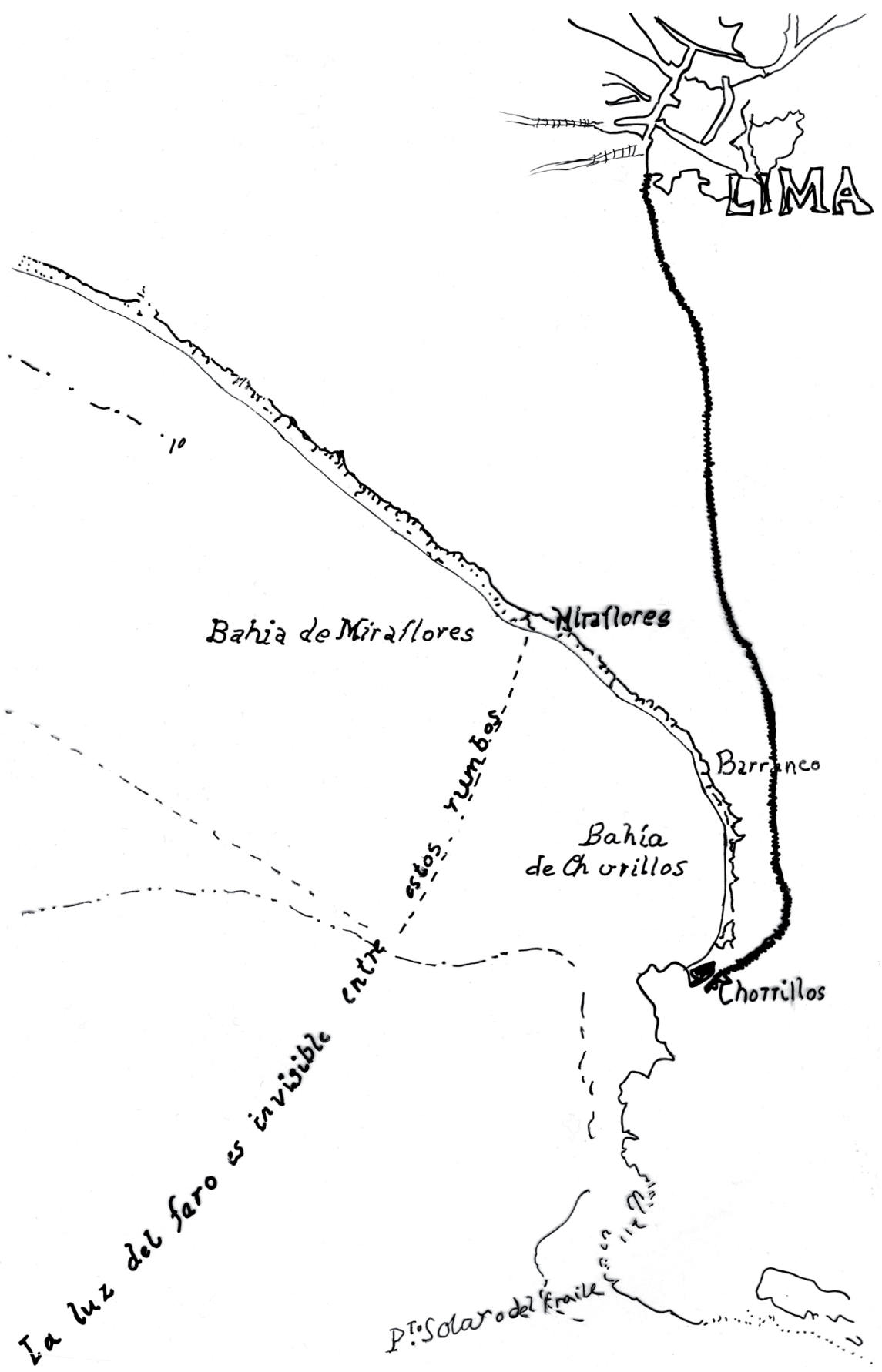

Figura 5. Trasparencia 3. Mapa de los distritos de Miraflores, Chorrillos y Barranco. Fuente y elaboración: Chávez 2017: 25. 
REVISTA KAWSAYPACHA: SOCIEDAD Y MEDIO AMBIENTE N 5 (2020)

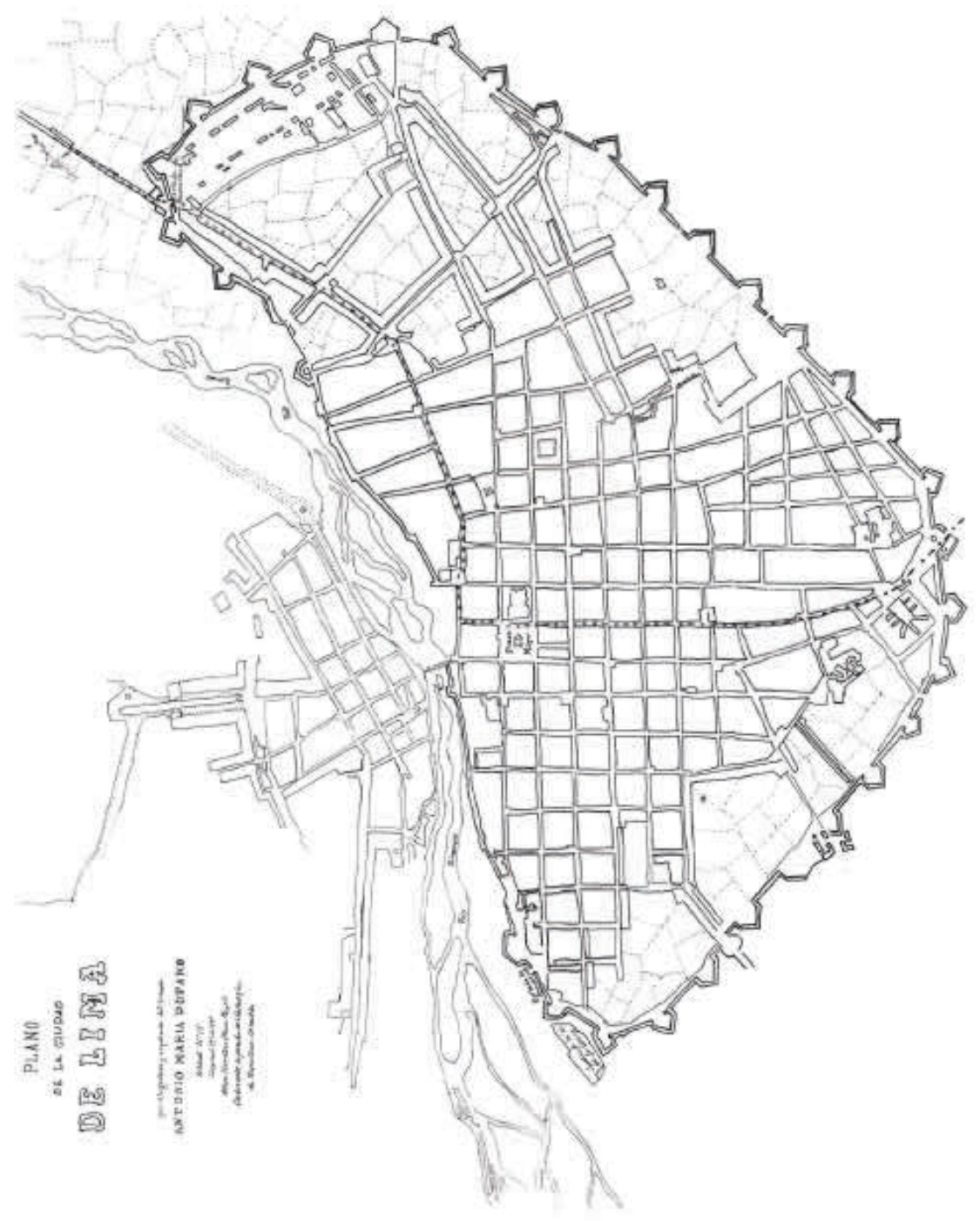


LA CONSTRUCCIÓN DEL TERRITORIO SIMBÓLICO Y SUS CARTOGRAFÍAS ÉTICO-ESTÉTICAS COMO MEMORIA VISUAL DE LOS PROCESOS DE PERTENENCIA... / KARLA VILLAVICENCIO MONTI

\section{«Nuestra ruta de 50 años»}

En su proyecto, el artista Ignacio $\mathrm{Mach}^{3}$ sostiene que las personas mayores de cincuenta años han vivido los procesos de cambio en Lima y han visto la explosión demográfica de los migrantes, en su mayoría provenientes de la zona andina, que ocuparon espacios periféricos de Lima, y comenta lo siguiente:

Las ocupaciones de estos espacios periféricos se han dado desde la década de los cuarenta o cincuenta del siglo xx. Estas personas tuvieron que adaptarse a estas condiciones del territorio haciendo uso de sus conocimientos (vivir en quebradas es algo que se da en población alto andina), como su organización social (se propicia el trabajo comunitario que es parte de su cultura). En consecuencia, muchos espacios de sociabilización de la Lima tradicional han tenido que modificar sus preferencias de público para acoger a estos nuevos sectores de la población emergente que hoy demandan ocupar esos espacios y que, luego de medio siglo, han cambiado el rostro de la capital. El trabajo propone señalar cómo se ha dado este proceso de ocupación de Lima por los migrantes de provincia en los últimos cincuenta años. Se genera un matriz a partir de la traza urbana del centro de Lima que se va modificando, todo esto aparentemente caótico comienza a ordenarse en la mente para darle un sentido y un significado. (Macha 2017: 46)

Su trabajo propone mostrar cómo se dieron estos procesos de ocupación en Lima, elaborando una matriz a partir de la traza urbana del Centro de Lima, la cual se va modificando en la alteración de la intensidad del color que obedece a la pigmentación generada de la sumatoria de los afiches «chicha» (sincretismo cultural y visual que emergió en las últimas décadas en Lima y que, entre una de sus tantas expresiones, se plasmaba en afiches pegados en la ciudad). Esta alteración de color empieza de abajo hacia arriba, donde el gris representa la Lima comprendida entre los años sesenta y los noventa, y el color que empieza a saturarse y su repetición generan una trama modular, creando un gran mosaico que resulta del trabajo de calado que dejan solo las vías.

\footnotetext{
3 Ignacio Macha, profesor de la Facultad de Arte y Diseño de la Pontificia Universidad Católica del Perú, autor del proyecto «Nuestra ruta de 50 años», desarrollado en el proyecto «Metrópolis imaginal: la guía de los viajes simbólicos en Lima» en 2016, a cargo de la doctora Karla Villavicencio, en el marco de la Cátedra Felipe Mac Gregor de Profesores Invitados 2016 PUCP.
} 


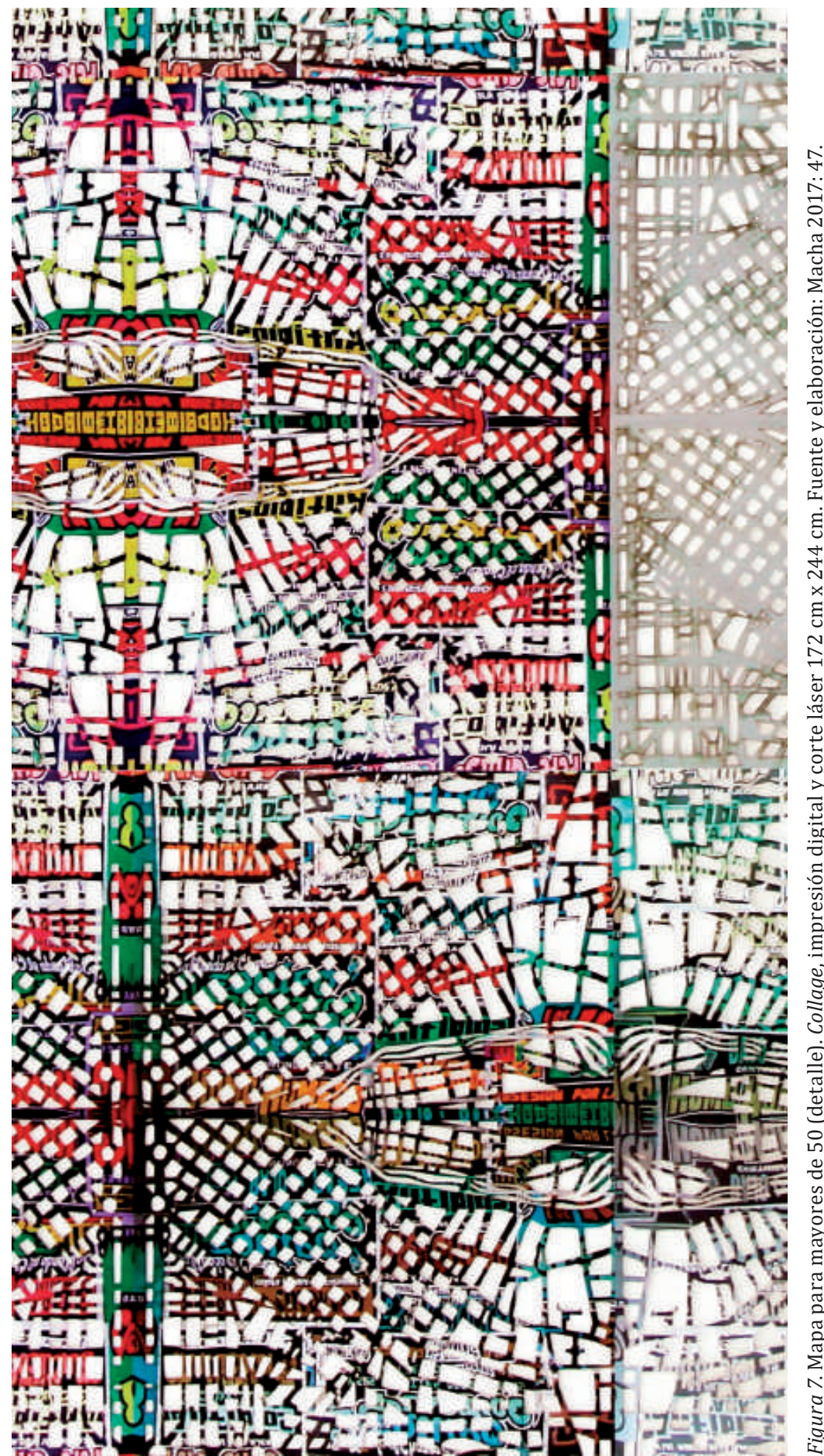




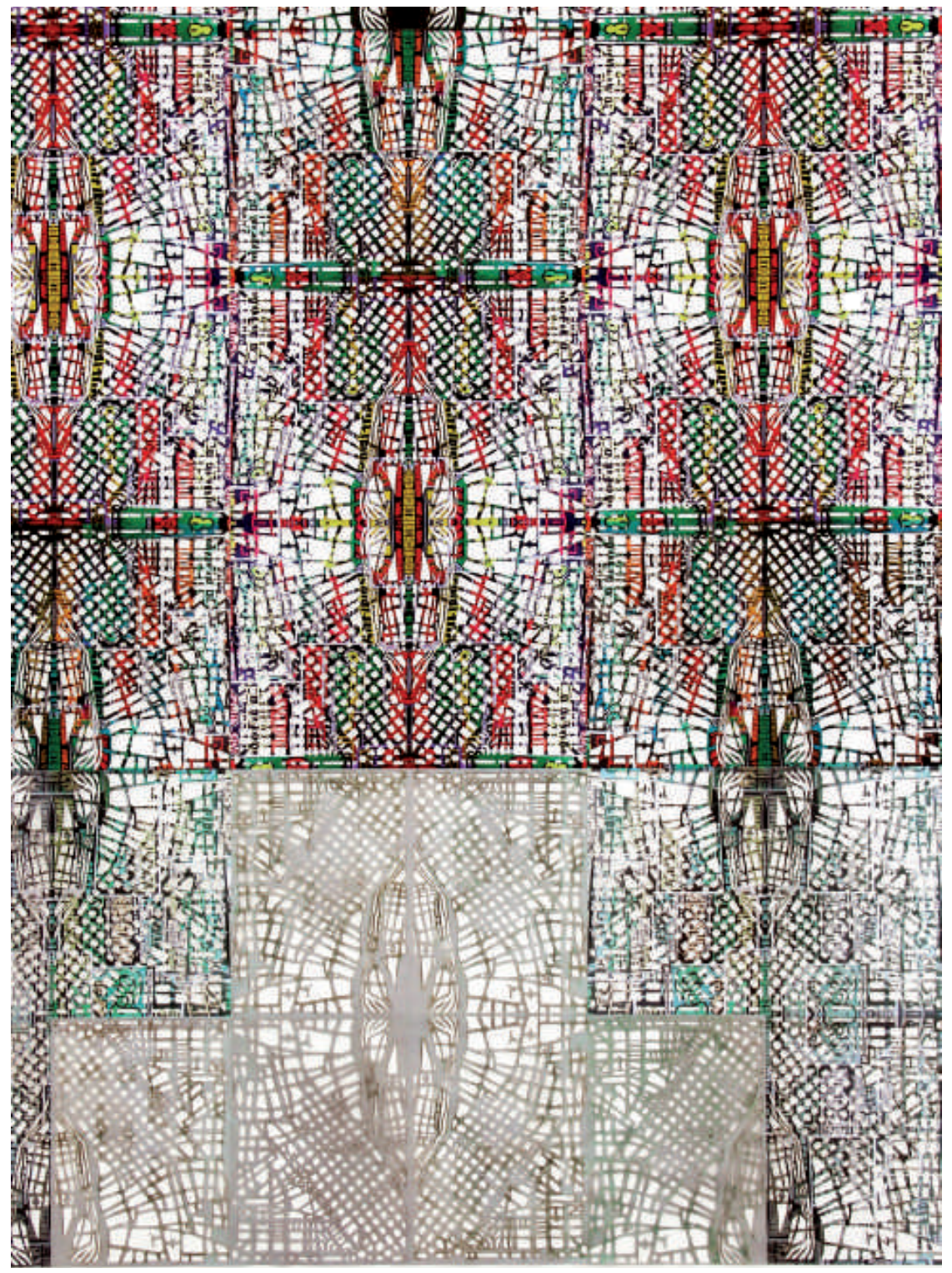

Figura 8. Mapa para mayores de 50. Collage, impresión digital y corte láser $172 \mathrm{~cm}$ x $244 \mathrm{~cm}$. Fuente y elaboración: Macha 2017: 47. 
Massey, en la entrevista «Hay que traer espacio a la vida», nos dice que el espacio se configura en la relación que establecen dos personas, o en la relación que establece un individuo con otro, la comunicación construye el espacio en sí mismo, sin esa relación hay un «vacío espacial».

Es probable que la razón por la que el espacio se ha vuelto parte de la agenda tenga mucho que ver con la globalización, y con el hecho de que ciertamente en el llamado «Primer Mundo», «Norte», «Occidente» (o como quieran llamarlo) estamos de pronto en el polo receptor de la globalización. El sur global —me refiero a América Latina y África- ha estado en el polo de recepción de la globalización por siglos, pero para nosotros (el Occidente) la desintegración del lugar, la multiplicidad de culturas, la hibridación, fue un gran shock.

[...] Así que en este sentido el espacio es la dimensión social, no como opuesto al tiempo, sino solamente porque no podríamos estar sentadas aquí juntas en el mismo momento si no hubiese espacio, y nosotras creamos espacio cuando lo hacemos (cuando nos sentamos juntas). La tercera proposición simplemente sigue a las dos primeras, y es que siempre estamos construyendo espacio a través de nuestras interacciones y nuestra ausencia de interacciones, y de todas las relaciones que nos constituyen, tanto humanas como no humanas. (2008: 330-331)

Esta definición de Massey es pertinente para entender que la clave de vivir el espacio desde sus valores comunitarios está en la posibilidad de comprensión de los problemas colectivos de una sociedad. En la experiencia de la docencia universitaria de pregrado en la Facultad de Arte y Diseño de la Pontificia Universidad Católica del Perú con los participantes del curso Proyectos Interdisciplinarios de la Ciudad y el Territorio (semestre 2016-2), se pudo comprobar esta precisión al analizar los alcances del proceso y del proyecto del grupo $\mathrm{CO}[\mathrm{HABITAR}]^{4}$.

Cabe señalar que los equipos de estudiantes se conformaron por los intereses comunes descubiertos en la producción del mapa personal y del mapa histórico; y por las afinidades encontradas al representar su relación con la ciudad y el territorio en Lima.

Podemos observar el proceso de estos dos mapas en la producción de Úrsula Cogorno, participante que luego pasó a integrar el grupo CO[HABITAR]; quien en el primer mapa representa los puntos de conexión que encontraba como los más resaltantes por su significación simbólica,

4 Conformado por un equipo de estudiantes: Claudia Ayala Andazabal, Arturo Cochatoma Serrano, Úrsula Cogorno Buendía, Luciana Melgar Carhuancho y Diandra Rodríguez Armas, tanto de la Facultad de Arquitectura como de la propia Facultad de Arte donde se realizó el curso. 
LA CONSTRUCCIÓN DEL TERRITORIO SIMBÓLICO Y SUS CARTOGRAFÍAS ÉTICO-ESTÉTICAS COMO MEMORIA VISUAL DE LOS PROCESOS DE PERTENENCIA... / KARLA VilLAVICENCIO MONTI

cada punto representaba aquellos lugares a los que constantemente se desplazaba, generando una especie de tejido articular de rutas transitadas entre un lugar y otro (Figura 9).

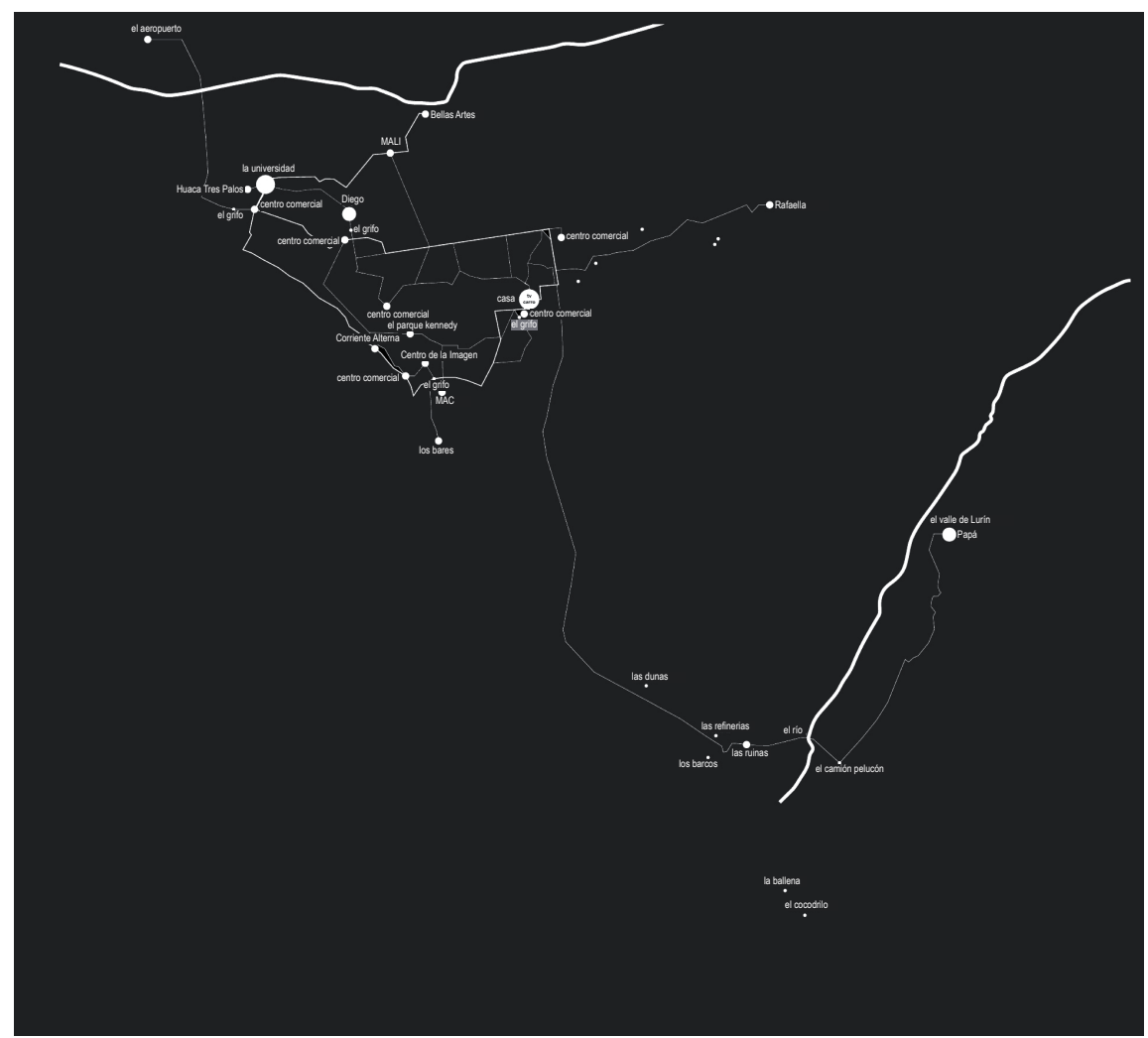

Figura 9. Presentación individual para el curso Proyectos Interdisciplinarios de la Ciudad y el Territorio. Fuente y elaboración: Cogorno 2016-2.

El segundo plano es una proyección cartográfica que, según la experiencia anterior de identificación de lugares personales de la autora, en este caso, identifica las huacas registradas en Lima Metropolitana, en un intento de hallazgo de la identidad cultural en el territorio que habita (Figura 10). 


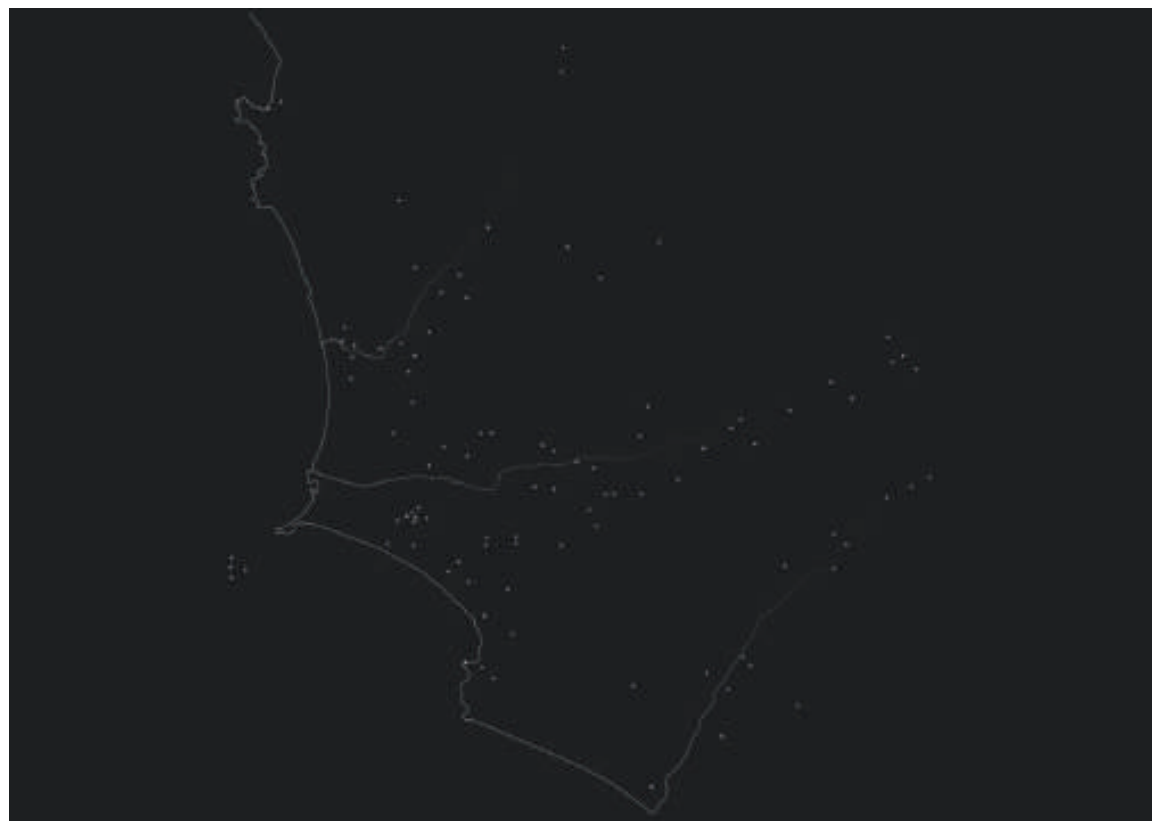

Figura 10. Presentación individual para el curso Proyectos Interdisciplinarios de la Ciudad y el Territorio. Fuente y elaboración: Cogorno 2016-2.

Los integrantes del curso entablaron debates argumentativos donde expusieron sus trabajos y resultados de los primeros dos mapas simbólicos (personal e histórico) y encontraron intereses afines para continuar con la tercera fase, definida como mapa imaginal en las experiencias anteriores, pero que en este caso se definiría como el desarrollo de una propuesta grupal abocada a plantear una visibilización de la problemática abordada y una visualización de las posibles intervenciones en la ciudad para resolverla.

A continuación, se explican las implicancias y los alcances del grupo CO[HABITAR]: el proyecto grupal propone un método que nace de acciones participativas para crear y fomentar la memoria y la identidad de nuestro país, generando una relación activa entre el complejo de Maranga, en el distrito de San Miguel, y los habitantes de la zona.

Este proyecto interdisciplinario es una propuesta de intervención artística que, a través de estrategias participativas y colaborativas, pretende construir de manera colectiva una comunidad capaz de visibilizar y difundir la presencia, el conocimiento y el significado del espacio arqueológico de la huaca Tres Palos, para hallar en su historia y memoria una identidad que nos permita fortalecer y hacer duraderos los lazos comunitarios (Ayala et al. 2016). 
LA CONSTRUCCIÓN DEL TERRITORIO SIMBÓLICO Y SUS CARTOGRAFÍAS ÉTICO-ESTÉTICAS COMO MEMORIA VISUAL DE LOS PROCESOS DE PERTENENCIA... / KARLA VillaVicEnCIO MONTi

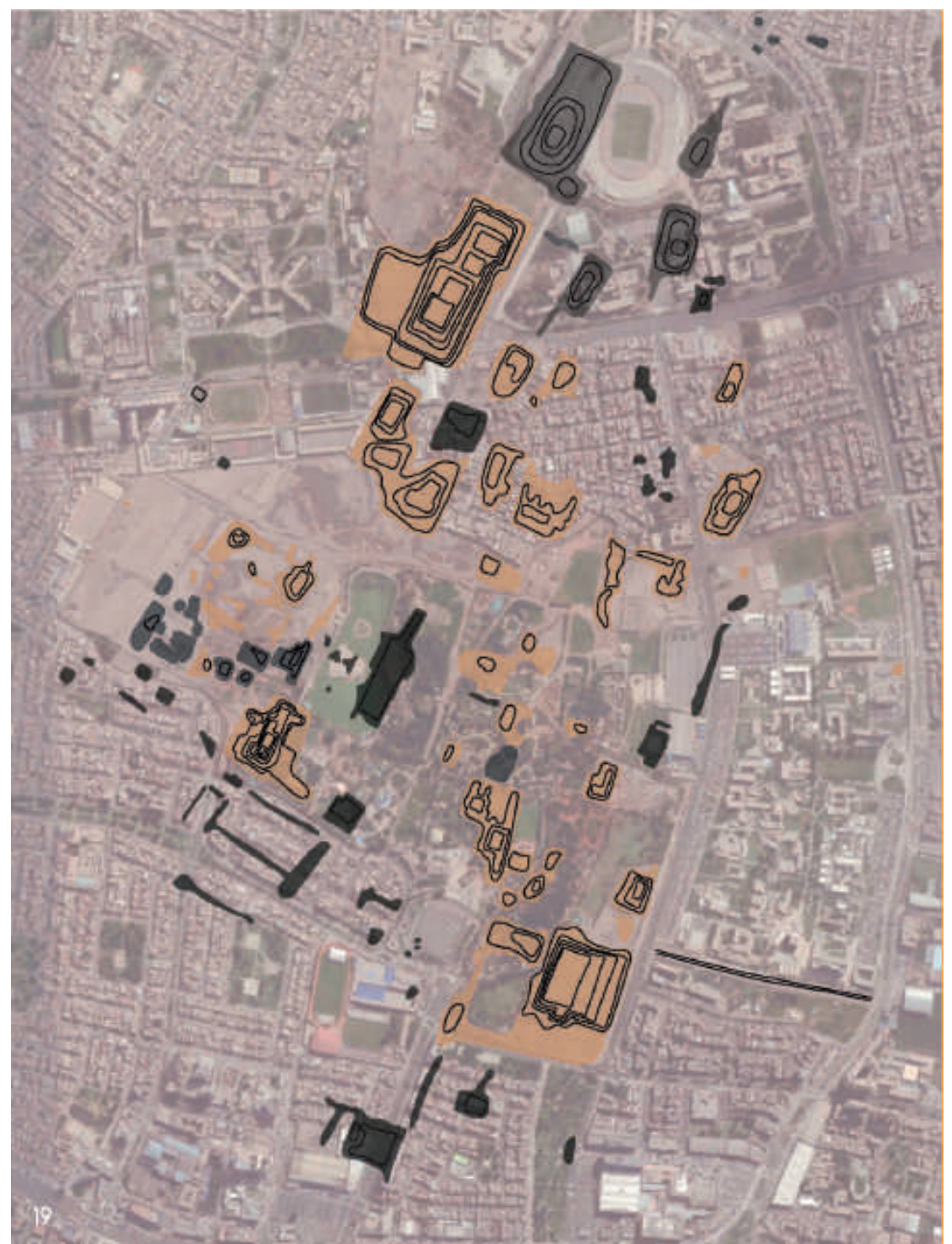

Figura 11. CO[HABITAR]. Proyectos interdisciplinarios de la ciudad y el territorio. Fuente y elaboración: Ayala et al. 2016: 19.

Los complejos arquitectónicos de las culturas prehispánicas de la costa central se han deteriorado o han desaparecido progresivamente debido a la superposición de un diseño urbanístico sobre las estructuras urbanas preexistentes desde la fundación española de Lima. Posteriormente, durante la República, la ciudad se expandió conectándose con los balnearios, sin embargo, no se consideraron dentro del planeamiento urbano los espacios arqueológicos y se los recluyó detrás de los muros, para protegerlos. Por 
último, en la época contemporánea surgieron las barriadas en las zonas norte, este y sur de la ciudad, como consecuencia de la migración, lo que ha tenido un impacto negativo para la conservación del patrimonio prehispánico debido a la ausencia de planeamiento urbano.

En el caso concreto de la huaca Tres Palos, que forma parte del complejo de Maranga y en la actualidad forma parte del Parque de Las Leyendas, esta se encuentra separada de su entorno por un muro enorme de concreto de tres metros de alto, revestido con paneles publicitarios, lo cual imposibilita la relación de los vecinos con el patrimonio arqueológico y el sentido de pertenencia respecto a este, lo cual acelera su deterioro (Ayala et al. 2016).

Ante esta situación y la inexistencia de estrategias y dinámicas de activación social e intervenciones que generen espacios de interacción entre la comunidad y el espacio arqueológico, se propone una solución que integre y articule la huaca a la ciudad. Esta consiste en una intervención artística que cree un recorrido con elementos fotográficos, que comunique de modo interactivo la historia y la importancia de la huaca Tres Palos, que permita a los transeúntes intervenir las piezas de forma libre y que recoja su opinión al respecto (Ayala et al. 2016).

Como se observa en las figuras 12, 13 y 14, el público elegido realizó una serie de intervenciones en la reproducción fotográfica de la huaca Tres Palos como resultado de los procesos de sensibilización y contextualización de la zona estudiada. Los insumos que se muestran en las imágenes y que consistieron en la producción de objetos diseñados facilitaron la recopilación de información mediante acciones participativas, como los paneles de acrílico explicativos, para luego promover la intervención dibujada sobre las fotografías de las posibles soluciones a la problemática abordada, lo cual permitió al público y a los integrantes del grupo imaginar las posibilidades de recuperación del patrimonio contenido en dicho territorio y su revaloración.

La arqueología monumental de nuestra historia es maravillosa; sin embargo, solo podemos encontrarnos inmersos del todo en el presente.

Modernización, urbanización, civilización, ese proceso de divorcio entre la vida y los cuentos que hace posible a cada cual «contar su vida» (y que también ejemplifican expresiones como «no me cuentes tu vida» $\mathrm{o}$ «no me vengas con historias») ese proceso mediante el cual la naturaleza se convirtió en red extensa calculable e insensible (espacio y tiempo vacíos) [...] el camino se puebla de innumerables restos arqueológicos que carecen de historia, imágenes y palabras sin naturaleza que quedan fuera del Gran Relato, restos sin unidad ni grandeza, a menudo ridículos. (Pardo 1996: 207) 
LA CONSTRUCCIÓN DEL TERRITORIO SIMBÓLICO Y SUS CARTOGRAFÍAS ÉTICO-ESTÉTICAS COMO MEMORIA VISUAL DE LOS PROCESOS DE PERTENENCIA... / KARLA VILLAVICENCIO MONTI

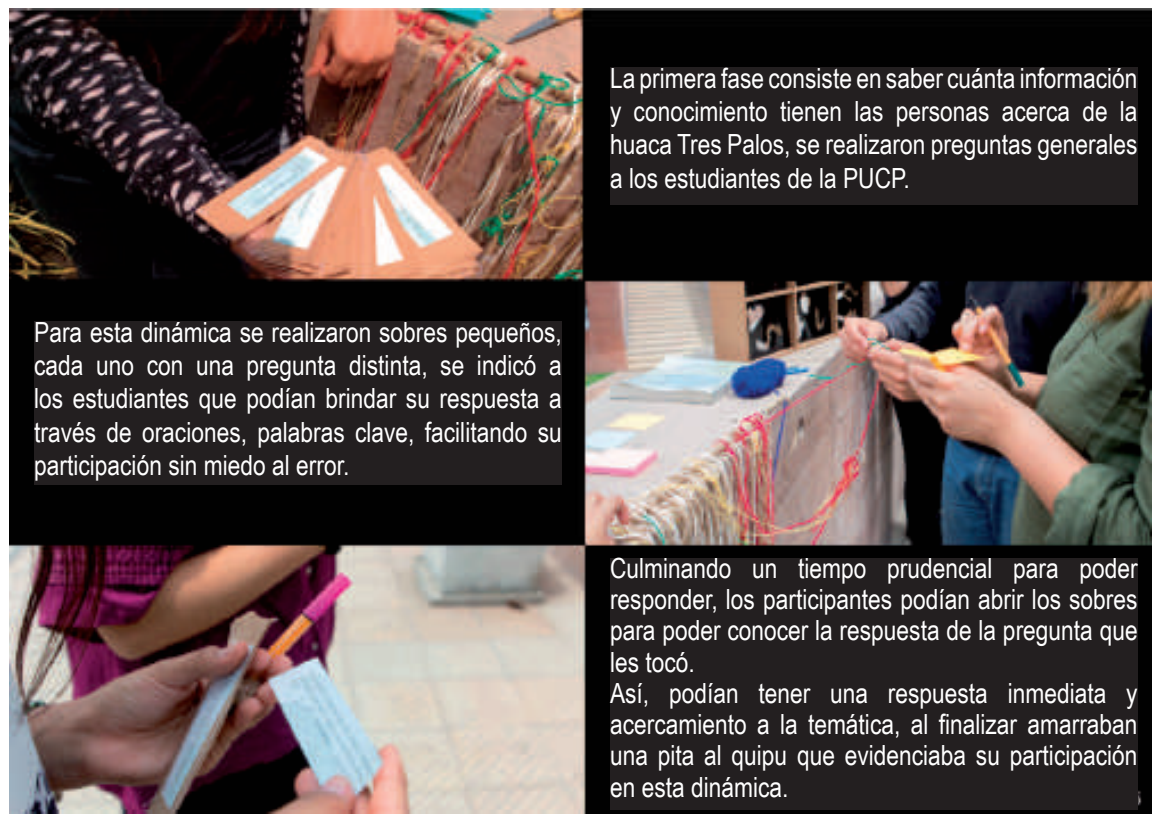

Figura 12. CO[HABITAR]. Proyectos interdisciplinarios de la ciudad y el territorio. Fuente y elaboración: Ayala et al. 2016: 35.
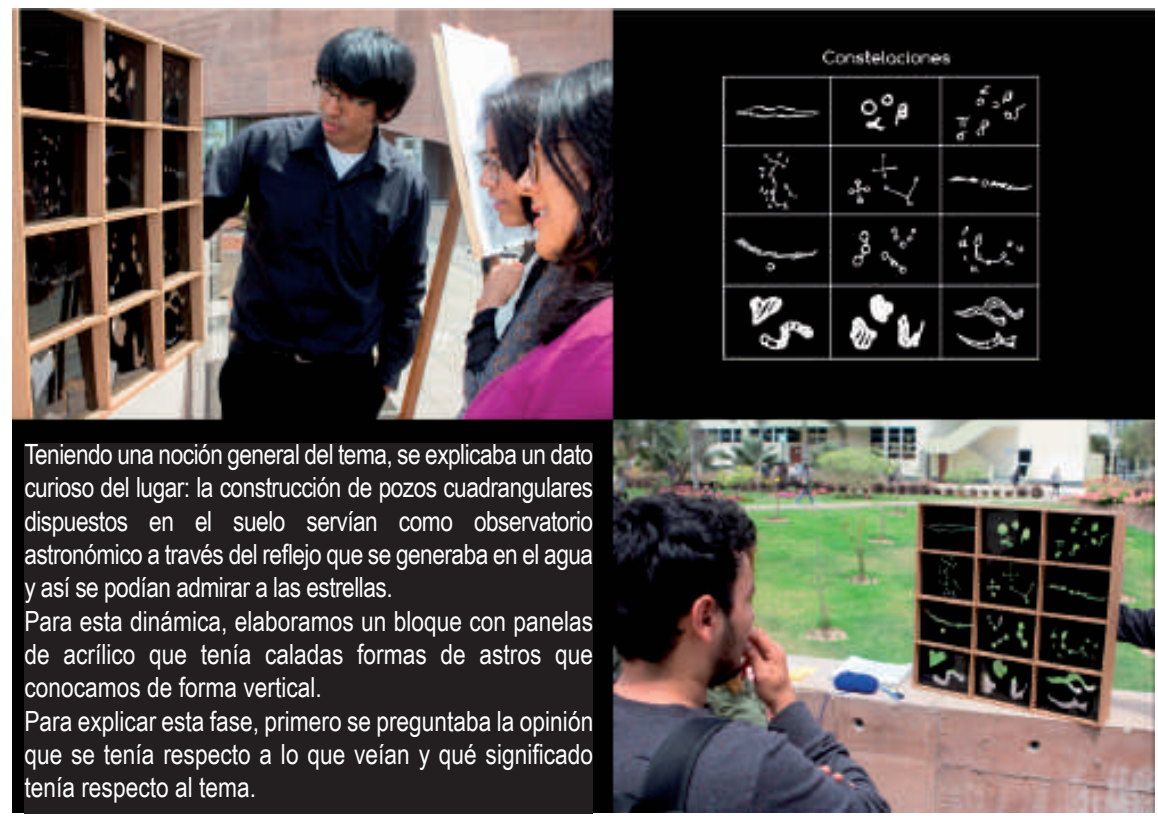

Teniendo una noción general del tema, se explicaba un dato curioso del lugar: la construcción de pozos cuadrangulares dispuestos en el suelo servían como observatorio astronómico a través del reflejo que se generaba en el agua y así se podian admirar a las estrellas.

Para esta dinámica, elaboramos un bloque con panelas de acrílico que tenía caladas formas de astros que conocamos de forma vertical.

Para explicar esta fase, primero se preguntaba la opinión que se tenía respecto a lo que veían y qué significado tenía respecto al tema.

Figura 13. $\mathrm{CO}$ [HABITAR]. Proyectos interdisciplinarios de la ciudad y el territorio. Fuente y elaboración: Ayala et al. 2016: 40. 
REVISTA KAWSAYPACHA: SOCIEDAD Y MEDIO AMBIENTE $N^{\circ} 5$ (2020)

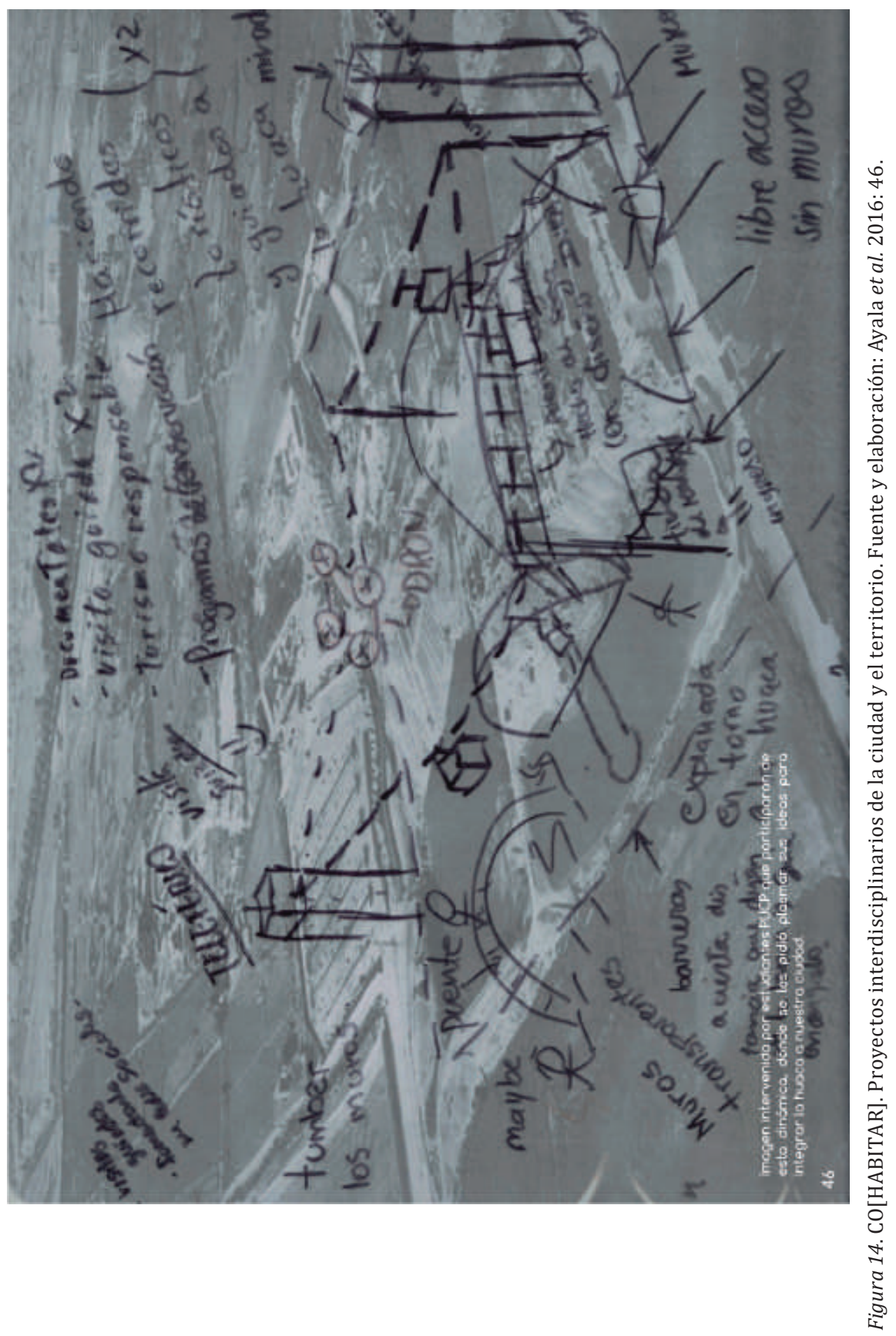




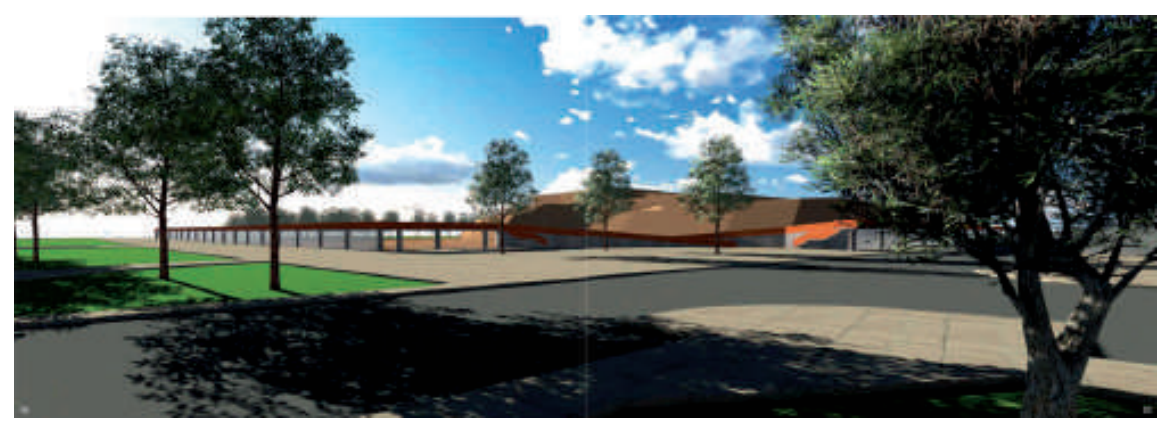

Figura 15. CO[HABITAR]. Proyectos interdisciplinarios de la ciudad y el territorio. Fuente y elaboración: Ayala et al. 2016: 55-56.

El territorio no se entiende como una arquitectura inmóvil y perenne, sino como la contención de un proceso de afincamiento donde lo colectivo es crucial para el desarrollo del grupo de habitantes. La estética es mutante, móvil, efímera en el territorio, pero ligada a una doble línea de representación. Aquí es donde aparece el rito, actuando desde la categoría de la experiencia simbólica. El rito va narrando una leyenda que unifica las actitudes del poblador a los comportamientos de eficacia asignados, devuelve así el tiempo mítico al instante de su reproducción. Hablamos de la movilización del propio ser, como ente que se adapta a las circunstancias del nuevo territorio disponible para sus fines físicos.

Un ser humano no puede existir como tal sino en el seno de una configuración formal, en un territorio y en una temporalidad que le preceden, que fundan sus condiciones de posibilidad, que constituyen sus raíces naturales, sus arraigos en la tierra, su comunidad. Por lo mismo, la naturaleza no existe más que cultivada por una cultura y por un culto, cantada por una lengua, contada por un cuento. (Pardo 1996: 267)

Estos ejemplos nos hablan visualmente de una memoria y transforman la inevitable historia de nuestros muertos. El pasado no está muerto, es necesario mantener una relación simbólica con lo que el transcurso del tiempo deja detrás del presente. Sobre este espacio dual la ciudad se eleva. Una ilusión, tal vez, pero ante todo una posibilidad, una forma simbólica de cerrar la ruptura del hogar primero, la desesperanza, los símbolos cruzados, mezclados. Márgenes convexos. Tiempo tangible en la vivienda e intangible en el rito. Sobre la subsistencia, el deseo de la existencia y de la vida se impone. Estética intangible que sintoniza al acorde de lo humano. 
REVISTA KAWSAYPACHA: SOCIEDAD Y MEDIO AMBIENTE $N^{\circ} 5$ (2020)

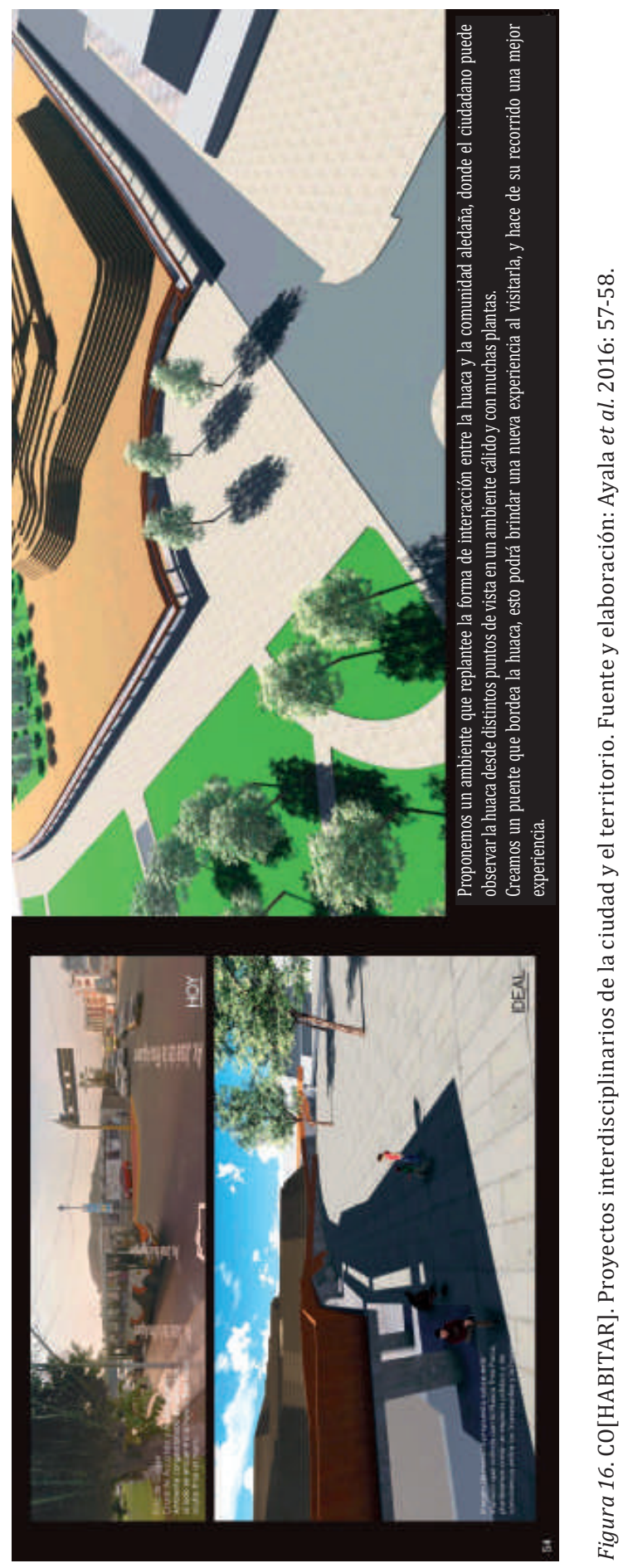


LA CONSTRUCCIÓN DEL TERRITORIO SIMBÓLICO Y SUS CARTOGRAFÍAS ÉTICO-ESTÉTICAS COMO MEMORIA VISUAL DE LOS PROCESOS DE PERTENENCIA... / KARLA VilLAVICENCIO MONTI

\section{Conclusión}

En los diversos ejemplos mostrados hablamos de un patrimonio intangible y de una reconquista del espacio donde el objetivo no es el «edificio», sino el proceso de adaptar la arquitectura a las necesidades de la comunidad, donde su integración implica el manejo y el desarrollo de códigos ético-estéticos, ya que se refieren a la utilización de códigos desarrollados a partir de la comprensión del complejo entramado que existe entre el conocimiento de nuestra historia personal y colectiva, sus elementos marginalizadores de segmentos y las relaciones socioculturales que se desarrollan en nuestra sociedad. Todo ello conforma el complejo entramado de la ciudad de Lima.

Si tuviéramos que dibujar una percepción simbólica de Lima, consideraríamos en efecto, diseñar un dibujo a modo de espirales que, aunque separadas y desarticuladas, son más flexibles y tienen posibilidades distintas de «pensarse» y de aportar una construcción distinta del territorio desde el aspecto simbólico.

La apreciación del paisaje desde el diálogo intercultural con todas sus implicancias, desde las históricas hasta las simbólicas, dependiendo del origen y de las experiencias de migración de individuos y grupos sociales, y sus condiciones antropológico-políticas, es determinante para comprender e insertar una valorización ético-estética del patrimonio cultural inmaterial de nuestra historia con sus expresiones artísticas.

El propósito de este artículo ha sido definir los vínculos del desarrollo territorial y urbano y las relaciones de este con los componentes éticoestéticos de la ciudad y el paisaje. En este sentido, se hace necesario analizar las estructuras de representación visual desde nuestra contemporaneidad, lo cual permitiría visibilizar el complejo entramado de situaciones incomprendidas de la ciudad.

Quizá así seamos más capaces de involucrarnos en la construcción de la ciudad posible para todos.

\section{Referencias}

Ansión, J., Mujica, L. \& Villacorta, A. (2008). Los que se quedan: familias de emigrados en un distrito de Lima. Lima: PUCP. CISEPA. Federación internacional de Universidades Católicas.

Ayala, C., Cochatoma, A., Cogorno, U., Melgar \& L., Rodríguez, D. (2016). CO[HABITAR]. Proyectos Interdisciplinarios de la Ciudad y el Territorio. Lima: Pontificia Universidad Católica del Perú. Coordinadora Dra. Karla Villavicencio Monti.

Chávez, C. (2017). En Villavicencio, K., Chávez, C., Díaz, L., Macha, I., Torres, M., Santisteban, E. \& Valenzuela, C. (2017). Metrópolis imaginal: la guía de 
los viajes simbólicos en Lima (pp. 10-29). Lima: Pontificia Universidad Católica del Perú. Departamento de Arte y Diseño.

Kahatt, S. (2016). Megaformas y formas colectivas: Estrategias para habitar la pendiente. En Rodríguez, L. y Muñoz, P. (Eds.). (2016) La ciudad de las laderas. Vivienda, ciudad y sociedad. Ensayos. Workshop Limápolis 2016. Lima: Fondo Editorial PUCP.

Macha, I. (2017). IGNACIO MACHA. En Villavicencio, K. et al. (2017). Metrópolis imaginal: la guía de los viajes simbólicos en Lima (pp. 38-47). Lima: Pontificia Universidad Católica del Perú. Departamento de Arte y Diseño.

Massey, D. (2008). Hay que traer el espacio a la vida/ Entrevistadoras: Román Velázquez, Patria y García Vargas, Alejandra. Román, P. y García, A. Hay que traer el espacio a la vida. Signo y Pensamiento, 27 (53), pp. 328343. Pontificia Universidad Javeriana Bogotá, Colombia. Recuperado de https://dspace.lboro.ac.uk/2134/26686

Pardo, J. (1996). La Intimidad. Valencia: Pre-textos.

Villavicencio, K., Chávez, C., Díaz, L., Macha, I., Torres, M., Santisteban, E. \& Valenzuela, C. (2017). Metrópolis imaginal: La guía de los viajes simbólicos en Lima. Lima: Pontificia Universidad Católica del Perú. Departamento de Arte y Diseño.

Villavicencio, K. (productor) y Villavicencio, K., Luque, J., A. (directores). (2014). ImaRginäre Städte/Ciudades Imarginales. [documental]. Viena/Lima: Ministerio de Cultura y Arte de Austria.

\section{Imágenes}

Figura 1. Chávez, C. (2017). «De Reducto 2 a la Portada de Maravillas. Hacia el descanso» (detalle). [Instalación]. En Villavicencio, K., Chávez, C., Díaz, L., Macha, I., Torres, M., Santisteban, E. \& Valenzuela, C. (2017). Metrópolis imaginal: la guía de los viajes simbólicos en Lima, p. 20. Lima: Pontificia Universidad Católica del Perú. Departamento de Arte y Diseño.

Figura 2. Chávez, C. (2017). «De Reducto 2 a la Portada de Maravillas. Hacia el descanso» [Instalación]. En Villavicencio, K. et al. (2017). Metrópolis imaginal: la guía de los viajes simbólicos en Lima, p.20. Lima: Pontificia Universidad Católica del Perú. Departamento de Arte y Diseño.

Figura 3. Chávez, C. (2017). Trasparencia 1. Mapa en referencia a la vida de Cecilia. [Mapa]. En Villavicencio, K. et al. (2017). Metrópolis imaginal: la guía de los viajes simbólicos en Lima, p.21. Lima: Pontificia Universidad Católica del Perú. Departamento de Arte y Diseño.

Figura 4. Chávez, C. (2017). Trasparencia 2. Mapa de las divisiones de la batalla de Reducto. [Mapa]. En Villavicencio, K. et al. (2017). Metrópolis imaginal: la guía de los viajes simbólicos en Lima, p. 23. Lima: Pontificia Universidad Católica del Perú. Departamento de Arte y Diseño. 
LA CONSTRUCCIÓN DEL TERRITORIO SIMBÓLICO Y SUS CARTOGRAFÍAS ÉTICO-ESTÉTICAS COMO MEMORIA VISUAL DE LOS PROCESOS DE PERTENENCIA... / KARLA VILLAVICENCIO MONTI

Figura 5. Chávez, C. (2017). Trasparencia 3. Mapa de los distritos de Miraflores, Chorrillos y Barranco. [Mapa]. En Villavicencio, K. et al. (2017). Metrópolis imaginal: la guía de los viajes simbólicos en Lima, p.25. Lima: Pontificia Universidad Católica del Perú. Departamento de Arte y Diseño.

Figura 6. Chávez, C. (2017). Trasparencia 4. Plano de la ciudad de Lima con guías de la antigua ruta del tren. [Mapa]. En Villavicencio, K. et al. (2017). Metrópolis imaginal: la guía de los viajes simbólicos en Lima, p.27. Lima: Pontificia Universidad Católica del Perú. Departamento de Arte y Diseño.

Figura 7. Macha, I. (2017). Mapa para mayores de 50 (detalle). [Collage]. En Villavicencio, K. et al. (2017). Metrópolis imaginal: la guía de los viajes simbólicos en Lima, p.47. Lima: Pontificia Universidad Católica del Perú. Departamento de Arte y Diseño.

Figura 8. Macha, I. (2017). Mapa para mayores de 50. [Collage]. En Villavicencio, K. et al. (2017). Metrópolis imaginal: la guía de los viajes simbólicos en Lima, p.47. Lima: Pontificia Universidad Católica del Perú. Departamento de Arte y Diseño.

Figuras 9, 10. Cogorno, U. (2016). [Mapa]. Presentación individual para el curso Proyectos Interdisciplinarios de la Ciudad y el Territorio.

Figuras 11, 12, 13, 14. Ayala, C., Cochatoma, A., Cogorno, U., Melgar, L. \& Rodríguez, D. (2016). [Fotografía]. En Ayala, C., Cochatoma, A., Cogorno, U., Melgar, L. y Rodríguez, D. (2016). CO[HABITAR]. Proyectos interdisciplinarios de la ciudad y el territorio, p. 19. Lima: Pontificia Universidad Católica del Perú.

Figuras 15, 16. Ayala, C., et al. (2016). [Modelado 3D]. En Ayala, C., et al. (2016). CO[HABITAR]. Proyectos interdisciplinarios de la ciudad y el territorio, pp. 55-56. Lima: Pontificia Universidad Católica del Perú. 